\title{
Fisiopatologia da Síndrome de Sjögren e sua dificuldade diagnóstica
}

\author{
Pathophysiology of Sjögren's Syndrome and its diagnostic difficulty \\ Fisiopatología del Síndrome de Sjögren y su dificultad de diagnóstico
}

Recebido: 06/06/2021 | Revisado: 10/06/2021 | Aceito: 11/06/2021 | Publicado: 26/06/2021

\author{
Cassia Vilar de Araújo \\ ORCID: https://orcid.org/0000-0002-7302-8093 \\ Centro Universitário do Vale do Ipojuca, Brasil \\ E-mail: cassiavilar@hotmail.com \\ Natália Millena Silva \\ ORCID: https://orcid.org/0000-0003-0356-2343 \\ Universidade Federal de Pernambuco, Brasil \\ E-mail: nataliamillena18@outlook.com \\ Pâmella Grasielle Vital Dias de Souza \\ ORCID: https://orcid.org/0000-0001-9884-9544 \\ Centro Universitário do Vale do Ipojuca, Brasil \\ E-mail: pamellagvds@gmail.com
}

\begin{abstract}
Resumo
A Síndrome de Sjögren é uma doença autoimune, caracterizada pela infiltração linfocitária no epitélio glandular, onde acomete principalmente as glândulas exócrinas salivares e lacrimais. O estudo mostra as classificações da síndrome e a relação dos autoanticorpos relacionados com seu diagnóstico. Foi realizada uma revisão de literatura integrativa, utilizando artigos publicados entre os anos de 2010 à 2020, nas línguas portuguesa, inglesa e espanhola que foram publicados de forma integra nos bancos de dados PubMed, SciELO e LILACS. A síndrome " Sicca" é causada por fatores genéticos, ambientais e hormonais. Acomete principalmente mulheres com idade média de 56 anos, onde vem sofrendo um desequilíbrio hormonal. A reação autoimune dar-se pela superestimulação das células $\mathrm{T}$ e células $\mathrm{B}$ que irão estimular a hipergamaglobulinemia e produção de autoanticorpos. A longo prazo as alterações podem sofrer mutações acarretando no desenvolvimento de linfoma não Hodgkin. A literatura mostra que o retardo do diagnóstico para a Síndrome de Sjögren dar-se pelos sutis sintomas que muitas vezes passam despercebidos ou são confundidos com outras patologias. O anti-Ro e o anti-La são os principais autoanticorpos mais frequentes em pacientes com SS.
\end{abstract}

Palavras-chave: Síndrome de Sjögren; Autoanticorpos; Glândulas exócrinas.

\begin{abstract}
Sjögren's Syndrome is an autoimmune disease, characterized by lymphocytic infiltration in the glandular epithelium, where it affects mainly the exocrine salivary and lacrimal glands. The study shows the classifications of the syndrome and the relation of autoantibodies related to its diagnosis. An integrative literature review was conducted, using articles published between the years 2010 and 2020, in Portuguese, English and Spanish languages that were published integrally in PubMed, SciELO and LILACS databases. Sicca syndrome is caused by genetic, environmental and hormonal factors. It affects mainly women with an average age of 56 years, where they have been suffering from hormonal imbalance. The autoimmune reaction is caused by the overstimulation of $\mathrm{T}$ cells and $\mathrm{B}$ cells that will stimulate hypergammaglobulinemia and the production of autoantibodies. In the long term the changes may mutate and lead to the development of non-Hodgkin lymphoma. The literature shows that the delay in diagnosis for Sjögren's Syndrome is due to the subtle symptoms that often go unnoticed or are confused with other pathologies. Anti-Ro and anti-La are the most frequent autoantibodies in patients with SS.
\end{abstract}

Keywords: Sjögren's syndrome; Autoantibodies; Exocrine glands.

\section{Resumen}

El síndrome de Sjögren es una enfermedad autoinmune, caracterizada por la infiltración linfocítica en el epitelio glandular, donde afecta principalmente a las glándulas exocrinas salivales y lacrimales. El estudio muestra las clasificaciones del síndrome y la relación de los autoanticuerpos relacionados con su diagnóstico. Se realizó una revisión bibliográfica integradora a partir de artículos publicados entre los años 2010 y 2020, en los idiomas portugués, inglés y español que fueron publicados íntegramente en las bases de datos PubMed, SciELO y LILACS. El síndrome de la "sicca" está causado por factores genéticos, ambientales y hormonales. Afecta principalmente a las mujeres con una edad media de 56 años, que sufren un desequilibrio hormonal. La reacción autoinmune está causada por la sobreestimulación de las células T y B que estimularán la hipergammaglobulinemia y la producción de autoanticuerpos. A largo plazo, estas alteraciones pueden sufrir mutaciones que conduzcan al desarrollo de un linfoma no Hodgkin. La literatura muestra que el retraso en el diagnóstico del Síndrome de Sjögren se debe a los sutiles 
síntomas que muchas veces pasan desapercibidos o se confunden con otras patologías. El anti-Ro y el anti-La son los principales autoanticuerpos más frecuentes en pacientes con SS.

Palabras clave: Síndrome de Sjögren; Autoanticuerpos; Glándulas exócrinas.

\section{Introdução}

Várias desordes autoimunes acometem a população mundial, onde suas causas ainda não são totalmente esclarecidas. Essas desordens acarretam na desregulação do próprio sistema imune e ao invés de proteger o organismo, irá ataca-lo produzindo autoanticorpos e gerando uma resposta inflamatória no próprio organismo (Costa et al., 2019). Entre as diversas patologias autoimunes, a Síndrome de Sjögren se destaca por ser a segunda doença autoimune mais comum (Flament et al., 2016).

Em 1892, Hadden, Leber, Mikulicz relataram o caso de um homem de 42 anos com queixas de boca seca e apresentando aumento da glândula parótida e infiltrado de células redondas nas glândulas lacrimais. Nos anos de 1925 e 1933, Gougerot e Sjögren, respectivamente, associaram esses achados a poliartrite e doença sistêmica. O sueco Henrik Sjögren em 1956, relatou em um estudo a história clínica detalhada e achados histopatológicos de 19 mulheres, com idades entre 29 e 72 anos, no qual 13 delas apresentaram artrite reumatoide associada a xeroftalmia e xerostalmia, quadro clínico este que é atualmente diagnosticado em associação com a Síndrome de Sjögren (Gomes et al., 2010).

A Síndrome de Sjögren (SS) é considerada uma afecção crônica, multissistêmica, que se caracteriza por disfunção das glândulas exócrinas, anormalidades sistêmicas de múltiplos órgãos e hiper-reatividade sorológica (Betim et al., 2015). Esta síndrome tem como uma de suas características a infiltração linfocitária, que atinge múltiplos órgãos, tendo uma maior afinidade por órgãos exócrinos, como glândulas salivares e lacrimais, levando esses órgãos a perda de funções e desencadeando um caso de xeroftalmia e xerostomia, caracterizada pela falta de lubrificação de olhos e boca, respectivamente (L. Santos et al., 2013).

A SS pode ocorrer em todas as idades, mas afeta principalmente mulheres durante a meia-idade, geralmente cerca de $2,7 \%$ da população geral, com uma relação entre os sexos na proporção de 9 mulheres para cada homem. O envolvimento sistêmico da síndrome estimula várias manifestações clínicas, contribuindo para um certo grau de défice no diagnóstico mais preciso, sendo, portanto, um dos fatores que contribui para um retardo no diagnóstico e tratamento da doença (A. Santos et al., 2013) .

Pelo fato da população e dos profissionais da saúde terem pouco conhecimento sobre a Síndrome de Sjögren e por essa doença ter um histórico de associação com outras doenças que tem características semelhantes, muitas vezes é erroneamente diagnosticada, sendo assim subdiagnosticada. Essa revisão de literatura tem como objetivo apresentar a fisiopatologia da doença, suas formas de classificação, os sintomas desencadeados, as patologias que se apresentam frequentemente associadas e os autoanticorpos relatados em casos notificados da síndrome. Esclarecendo se os autoanticorpos auxiliam no diagnóstico, quais autoanticorpos estão relacionados e se eles são específicos para o diagnóstico.

\section{Metodologia}

Essa revisão de literatura integrativa foi elaborada num estudo de cunho qualitativo e caráter descritivo/exploratório baseados nos métodos descrito por Estrela (2018), estruturada numa pesquisa exploratória na literatura, ou seja, a partir de material já elaborado, tendo por objetivo analisar artigos e pesquisas relacionadas com os temas: Síndrome de Sjögren, Síndrome de Sjögren e autoanticorpos, Diagnóstico e tratamento da Síndrome de Sjögren, Associação da Síndrome de Sjögren e doenças autoimunes. Com intuito de levantar dados acerca do assunto, colaborando com a população e comunidade cientifica. 
Para que esse estudo tenha sido realizado foram usados critérios de inclusão como a seleção de artigos que tratem de assuntos relacionados ao tema, publicados entre os anos de 2010 e 2021, em idiomas da língua portuguesa, inglesa ou espanhola e que tenha sido disponibilizado de forma íntegra. Foram utilizados os artigos acadêmicos disponibilizados nos bancos de dados e plataformas cientificas como: Scientific Eletronic Library Online (SciELO), Literatura Latino-Americana e do Caribe em Ciências da Saúde (LILACS) e National Library of Medicine (PubMed), utilizando os descritores: Síndrome de Sjögren; Autoanticorpos; Diagnóstico; Tratamento; Doenças autoimune. Para a indexação dos artigos foram utilizados os operadores booleanos AND e OR. Foram pré-selecionados 19 artigos, onde foi realizada a leitura dos resumos, onde prosseguiu-se com à análise e organização das temáticas. O esquema utilizado para a escolha dos artigos está representado na Figura 1.

Figura 1: Esquema para seleção de artigos.

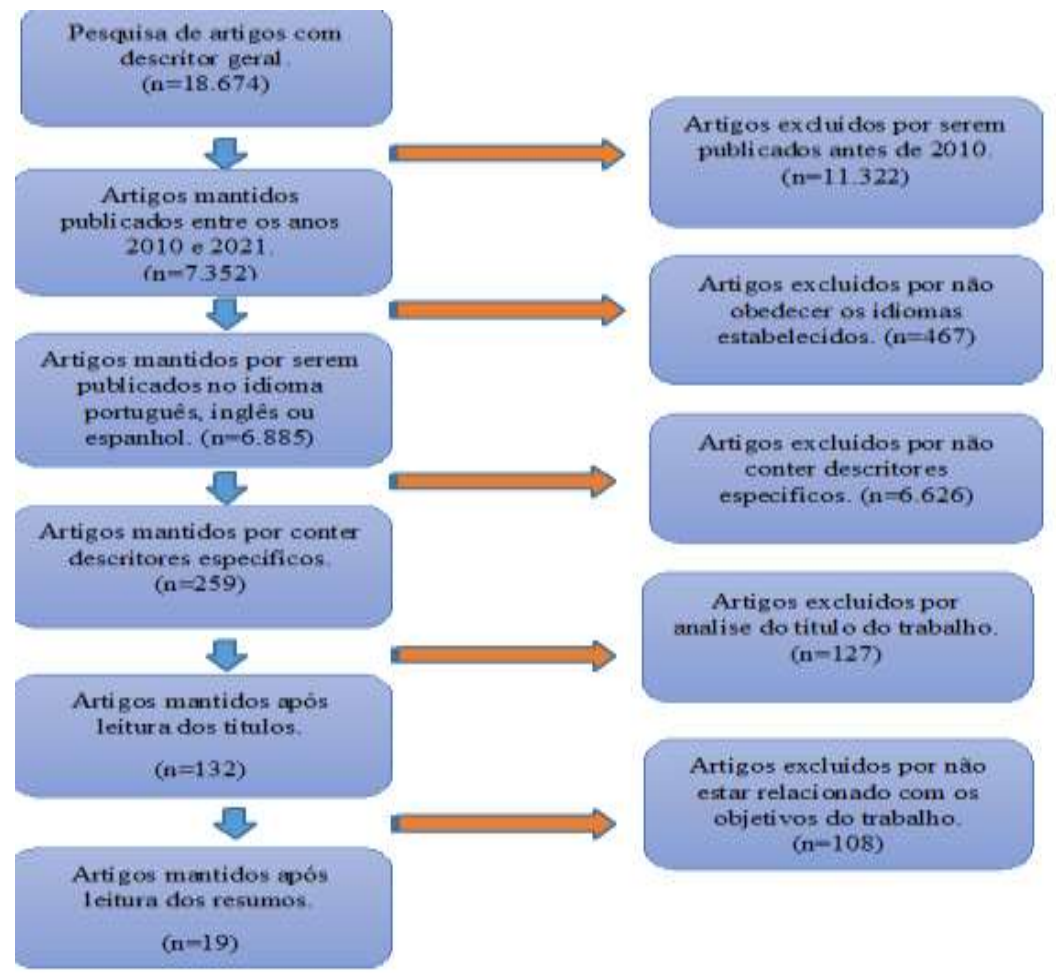

Fonte: Autores.

Para a análise e posterior síntese dos artigos que atenderão os critérios de inclusão foram utilizados quadros sinópticos especialmente construído para esse fim, que contemplou os seguintes aspectos, considerados pertinentes: título da pesquisa; autores/ano de publicação; intervenção estudada; resultados; recomendações/conclusões. A apresentação dos resultados e discursão dos dados obtidos foi feita de forma descritiva, possibilitando ao leitor a avaliação da aplicabilidade da revisão integrativa elaborada, de forma a atingir o objetivo desse método e da pesquisa, ou seja, descrever a fisiopatologia da Síndrome de Sjogren e conhecer os empecilhos que dificultam seu diagnóstico, buscando esclarecimentos que nos promovam um diagnóstico precoce que nos proporcionem ofertar o bem-estar para o paciente. 


\section{Resultados e Discussão}

Durante a pesquisa de artigos para o presente estudo, foram encontrados cerca de 18.674 contendo o descritor Síndrome de Sjögren, sendo em seguida utilizados novos descritores e filtros para afunilar a pesquisa e encontrar os artigos de maior relevância para compor este estudo, buscando principalmente informações mais atuais possíveis.

Esta revisão integrativa obteve treze artigos principais que atenderam os critérios de inclusão, pois apresentam em seu foco de análise pontos relacionados aos objetivos dos estudos como a fisiopatologia, atualização dos critérios diagnósticos, autoanticorpos relacionados e classificação da SS.

O Quadro 1 apresenta as sínteses dos artigos incluídos na revisão, coletados após leitura de forma integra dos mesmos.

Quadro 1: Apresentação da síntese de artigos incluídos na revisão.

\begin{tabular}{|c|c|c|c|c|}
\hline Título & Autores/ Ano & Intervenção estudada & Resultado & Recomendações/Conclusão \\
\hline $\begin{array}{l}\text { The meaning of anti-Ro and } \\
\text { anti-La antibodies in } \\
\text { primarySjögren`ssyndrome }\end{array}$ & $\begin{array}{l}\text { Molina; } \\
\text { Alegre; } \\
\text { Peregrina; } \\
2010\end{array}$ & $\begin{array}{l}\text { Os autores mostram a } \\
\text { associação dos } \\
\text { anticorpos anti-Ro/SSa e } \\
\text { anti-La/SSB com o o } \\
\text { histórico de HLA, } \\
\text { disfunção demográfica, } \\
\text { clínica, glandulares, } \\
\text { outras características } \\
\text { sorológicas e resposta ao } \\
\text { tratamento. }\end{array}$ & $\begin{array}{l}\text { Os anticorpos anti-Ro/SSA e } \\
\text { anti-La/SSB está presente em } \\
\text { pacientes com síndrome de } \\
\text { sjögren, tendo associação com } \\
\text { manifestações glandulares e } \\
\text { extraglandulares.O HLA classe } \\
\text { II participa na perpetuação e } \\
\text { início da resposta autoimune. }\end{array}$ & $\begin{array}{l}\text { Os anticorpos anti-Ro/SSA e anti- } \\
\text { La/SSB são uteis no diagnóstico da } \\
\text { síndrome de sjögren, mas não são } \\
\text { parâmetros sorológicos para avaliar a } \\
\text { resposta ao tratamento a depleção de } \\
\text { células B. }\end{array}$ \\
\hline $\begin{array}{l}\text { B cells in Sjögren`s syndrome: } \\
\text { from pathophysiology to } \\
\text { diagnosis and treatment }\end{array}$ & $\begin{array}{l}\text { Cornec; } \\
\text { Pensec; } \\
\text { Tobón; } \\
\text { Pers; } \\
\text { Joulin; } \\
\text { Saraux; } \\
2012\end{array}$ & 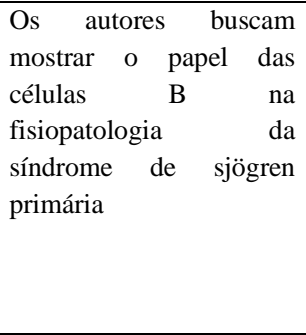 & \begin{tabular}{lrr} 
As células & B & são \\
superestimuladas & \multicolumn{2}{c}{ produzindo } \\
excessivas quantidades & de \\
imunoglobulinas e & vários \\
autoanticorpos. & Essa \\
superestimulação das células B \\
podem levar
\end{tabular} & $\begin{array}{l}\text { As pesquisas dessas respostas } \\
\text { imunológicas nos levam a dados que } \\
\text { devem ser usados no desenvolvimento } \\
\text { de novas abordagens terapêuticas. }\end{array}$ \\
\hline $\begin{array}{l}\text { The Immune Factors Involved } \\
\text { in the Pathogenesis, Diagnosis, } \\
\text { and Treatment of Sjogren's } \\
\text { Syndrome }\end{array}$ & $\begin{array}{l}\text { Huang; } \\
\text { Cheng; } \\
\text { Jiang; } \\
\text { An; } \\
\text { Xiao; } \\
\text { Gou; } \\
\text { Yu; } \\
\text { Lei; } \\
\text { Chen; } \\
\text { Wang; } \\
\text { Wang; } \\
2013\end{array}$ & $\begin{array}{l}\text { Os autores abordam as } \\
\text { patogêneses da síndrome } \\
\text { de sjögren e seu } \\
\text { diagnóstico. }\end{array}$ & $\begin{array}{l}\text { A SS é uma doença autoimune } \\
\text { multifatorial, onde as células e } \\
\text { as Citocinas interagem } \\
\text { promovendo o desenvolvimento } \\
\text { da síndrome. Os fatores } \\
\text { genéticos envolvidos na } \\
\text { síndrome, são técnicas } \\
\text { promissoras } \\
\text { identificação. }\end{array}$ & $\begin{array}{l}\text { Sendo os fatores imunológicos um } \\
\text { ponto chave para o desenvolvimento de } \\
\text { tratamentos, vê-se necessário praticar } \\
\text { mais ensaios clínicos antes de sua } \\
\text { aplicação. }\end{array}$ \\
\hline $\begin{array}{l}\text { A comprehensive review of } \\
\text { autoantibodies } \\
\text { primarysjögren in } \\
\text { clinical phenotypes and } \\
\text { regulatory mechanisms }\end{array}$ & $\begin{array}{l}\text { Kyriakidis; } \\
\text { Kapsogeorgou; } \\
\text { Tzioufas; } \\
2013\end{array}$ & $\begin{array}{l}\text { Os autores discutem as } \\
\text { principais respostas } \\
\text { humorais autoimunes, o } \\
\text { avanço sobre as células } \\
\text { epiteliais no seu } \\
\text { desenvolvimento e seu } \\
\text { mecanismo regulatório. }\end{array}$ & $\begin{array}{l}\text { As células epiteliais das } \\
\text { glândulas salivares são capazes } \\
\text { de mediar a exposição de } \\
\text { autoantigenos ao sistema } \\
\text { imunológico por apoptose } \\
\text { elevada e liberação de } \\
\text { autoantigenos em corpos } \\
\text { apoptóticos pela secreção de } \\
\text { exossomos. }\end{array}$ & $\begin{array}{l}\text { São necessários estudos para elucidar a } \\
\text { regulação da expressão de } \\
\text { autoantigenos, como a produção de } \\
\text { autoanticorpos e a patogenicidade na } \\
\text { síndrome de sjögren, possibilitando a } \\
\text { produção de processos terapêuticos. }\end{array}$ \\
\hline $\begin{array}{l}\text { ChildhoodSjögren syndrome: } \\
\text { insights from adults and animal } \\
\text { models }\end{array}$ & $\begin{array}{l}\text { Lieberman; } \\
2013\end{array}$ & $\begin{array}{l}\text { Os autores discutem as } \\
\text { dificuldades no } \\
\text { diagnóstico da Síndrome } \\
\text { de Sjögren na infância, } \\
\text { mostra as descobertas } \\
\text { recentes no tratamento da } \\
\text { SS. }\end{array}$ & $\begin{array}{l}\text { O estudo com rituximabe } \\
\text { mostra um potencial terapêutico } \\
\text { na SS em adultos e novas } \\
\text { formas terapêuticas promissoras } \\
\text { vem sendo testadas como } \\
\text { terapia gênica e transferência de } \\
\text { células-tronco mesenquimas. }\end{array}$ & $\begin{array}{l}\text { A Síndrome de Sjögren na infância é } \\
\text { uma doença autoimune mal definida e } \\
\text { subdiagnosticada necessitando de } \\
\text { critérios especificos para criança. }\end{array}$ \\
\hline
\end{tabular}




\begin{tabular}{|c|c|c|c|c|}
\hline $\begin{array}{l}\text { Advances in the } \\
\text { understandingand treatment of } \\
\text { systemic complications in } \\
\text { Sjögren`s síndrome }\end{array}$ & $\begin{array}{l}\text { Brito-zerón; } \\
\text { Ramos-Casals; } \\
2014\end{array}$ & $\begin{array}{l}\text { Relatar a caracterização } \\
\text { clínica, o manejo } \\
\text { diagnóstico e terapêutico } \\
\text { da Síndrome de Sjögren } \\
\text { sistêmico }\end{array}$ & $\begin{array}{l}\text { O envolvimento sistêmico } \\
\text { desempenha um papel } \\
\text { fundamental no prognóstico da } \\
\text { síndrome de Sjögren primária }\end{array}$ & $\begin{array}{l}\text { Os autoanticorpos são sinais para um } \\
\text { diagnóstico precoce, sua positividade } \\
\text { confirma uma origem autoimune e pode } \\
\text { aparecer anos antes do diagnóstico da } \\
\text { doença. A via biológica de bloqueio } \\
\text { direto ou indireto das células B } \\
\text { apresenta uma forma promissora de } \\
\text { tratamento para a SS. }\end{array}$ \\
\hline $\begin{array}{l}\text { Anti-alpha-fodrin antibodies in } \\
\text { patients with Sjögren's } \\
\text { syndrome secondary to } \\
\text { rheumatoid arthritis }\end{array}$ & $\begin{array}{l}\text { Nisihara; } \\
\text { Skare; } \\
\text { Cenci; } \\
\text { Gabardo; } \\
\text { Nass; } \\
\text { Utiyama; } \\
2016\end{array}$ & $\begin{array}{l}\text { Investigar o anticorpo } \\
\text { anti-AF em um grupo de } \\
\text { pacientes com AR com e } \\
\text { sem SS secundária } \\
\text { (SSS). }\end{array}$ & 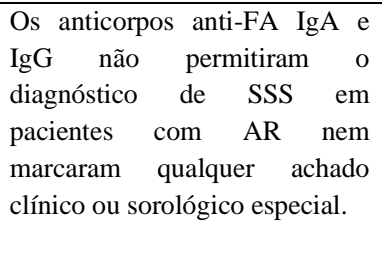 & $\begin{array}{l}\text { Sugere que seja realizada novas } \\
\text { investigações para verificar associação } \\
\text { com as classes de anticorpos. }\end{array}$ \\
\hline Primary sjögren`s syndrome & $\begin{array}{l}\text { Rischmueller; } \\
\text { Tieu; } \\
\text { Lester; } \\
2016\end{array}$ & $\begin{array}{l}\text { Os autores abordam as } \\
\text { várias formas } \\
\text { diagnósticas para a } \\
\text { Síndrome de sjögren, } \\
\text { mostrando os principais } \\
\text { avanços recentes. }\end{array}$ & $\begin{array}{l}\text { Os pacientes de SS apresentam } \\
\text { manifestação sistêmica e em } \\
15 \% \text { dos casos são graves, } \\
\text { afetando principalmente as } \\
\text { articulações, pele, pulmão e o } \\
\text { sistema nervoso central. Seu } \\
\text { diagnóstico é complexo e } \\
\text { requer uma avaliação gradual } \\
\text { para detectar riscos de } \\
\text { complicações sistêmicas. }\end{array}$ & $\begin{array}{l}\text { Os autores recomendam que estudos } \\
\text { observacionais e ensaios controlados } \\
\text { sejam usados para uma melhor } \\
\text { definição da história da doença, } \\
\text { patogênica, prognósticos e estratégias } \\
\text { terapêuticas, na busca de um } \\
\text { diagnóstico rápido e preciso. }\end{array}$ \\
\hline $\begin{array}{l}\text { Secondary } \text { Sjogren's Syndrome } \\
\text { in } 83 \quad \text { Patients With } \\
\text { Rheumatoid Arthritis }\end{array}$ & $\begin{array}{l}\text { Hajiabbasi } \\
\text { Masooleh; } \\
\text { Alizadeh; } \\
\text { Banikarimi; } \\
\text { Parsa, } \\
2016\end{array}$ & $\begin{array}{l}\text { Determinar a prevalência } \\
\text { de Síndrome de Sjögren } \\
\text { secundária, sintomas de } \\
\text { sicca,testes de anticorpos } \\
\text { positivos, UWSFR, teste } \\
\text { de Schirmer e Lissamina }\end{array}$ & $\begin{array}{l}\text { Houve uma associação } \\
\text { significativa entre a duração da } \\
\text { AR e a presença de sintomas de } \\
\text { sicca. O UWSFR positivo foi } \\
\text { significamente mais comum em } \\
\text { pacientes com AR com } \\
\text { sintomas de sicca e sem } \\
\text { sintomas de sicca.Não houve } \\
\text { um achado tão significatico } \\
\text { para teste de Schirmer positivo } \\
\text { ou Lissamina positivo. }\end{array}$ & $\begin{array}{l}\text { Os autores relatam uma tendência linear } \\
\text { significativa entre o envelhecimento e } \\
\text { os sintomas de secura. O UWSFR e } \\
\text { teste de Lissamina foram } \\
\text { significamente mais comum em } \\
\text { pacientes com Síndrome de Sjögren } \\
\text { secundária em comparação aqueles sem } \\
\text { ele. }\end{array}$ \\
\hline $\begin{array}{l}\text { Reviewing } \\
\text { Sjögren's syndrome: beyond } \\
\text { the dryness - } r \text { From } \\
\text { pathophysiology to diagnosis } \\
\text { and treatment }\end{array}$ & $\begin{array}{l}\text { Both; } \\
\text { Dalm; } \\
\text { Hagen; } \\
\text { Daele; } \\
2017\end{array}$ & $\begin{array}{lrr}\text { Apresentar } & \text { os } & \text { aspectos } \\
\text { clínicos } & \text { da } & \text { SSp, } \\
\text { enfatizando } & & \text { suas } \\
\text { manifestações sistêmicas. }\end{array}$ & $\begin{array}{l}\text { O tratamento da Ssp é eficaz } \\
\text { incluindo a terapia local e } \\
\text { sistêmica. Atualmente usa-se } \\
\text { tratamentos baseados em órgão, } \\
\text { utilizando produtos biológicos. }\end{array}$ & $\begin{array}{l}\text { É necessário novas pesquisas para } \\
\text { estudar novos alvos etiológicos para } \\
\text { terapia, avaliando a eficácia dos atuais } \\
\text { tratamentos. }\end{array}$ \\
\hline $\begin{array}{l}\text { The Diagnosis and Treatment } \\
\text { of Sjögren's Syndrome }\end{array}$ & $\begin{array}{l}\text { Stefanski; } \\
\text { Tomiak; } \\
\text { Pleyer; } \\
\text { Dietrich; } \\
\text { Burmester; } \\
\text { Dörner; } \\
2017\end{array}$ & $\begin{array}{l}\text { Conhecer a } \\
\text { epidemiologia da doença, } \\
\text { bem como suas } \\
\text { classificações, } \\
\text { patogenicidade, riscos e } \\
\text { tratamento. }\end{array}$ & $\begin{array}{l}\text { A Síndrome de Sjögren se } \\
\text { apresenta de várias formas; a } \\
\text { análise de testes sorológicos } \\
\text { permite a análise dos } \\
\text { autoanticorpos. Pacientes com } \\
\text { SS tem elevadas chances de } \\
\text { desenvolver linfoma não } \\
\text { Hodigkin. }\end{array}$ & $\begin{array}{l}\text { Pacientes com SS necessitam de } \\
\text { cuidados multidisciplinar; Tratamentos } \\
\text { farmacológicos e não farmacológicos } \\
\text { devem ser utilizados para manter o } \\
\text { controle da doença permitindo o bem } \\
\text { estar do paciente. }\end{array}$ \\
\hline $\begin{array}{l}\text { Ten-year observation of } \\
\text { patients with primary Sjögren's } \\
\text { syndrome: Initial presenting } \\
\text { characteristics and the } \\
\text { associated outcomes }\end{array}$ & $\begin{array}{l}\text { Tsukamoto; } \\
\text { Suzuki; } \\
\text { Takeuchi, } \\
2018\end{array}$ & $\begin{array}{l}\text { Identificar os casos } \\
\text { clínicos e imunológicos } \\
\text { iniciais associados a } \\
\text { manifestações } \\
\text { subsequentes em } \\
\text { pacientes com Síndrome } \\
\text { de Sjögren primária. }\end{array}$ & $\begin{array}{l}\text { Os pacientes com envolvimento } \\
\text { extraglandular ocorreu com } \\
\text { maior frequência em pacientes } \\
\text { com hiper-igG. O envolvimento } \\
\text { de órgãos extraglandulares } \\
\text { ocorreu com mais frequência } \\
\text { em pacientes positivos para } \\
\text { fator reumatoide (FR). }\end{array}$ & $\begin{array}{l}\text { Os autores concluíram que pacientes de } \\
\text { SSp com Fr e hiper-igG no diagnóstico } \\
\text { tem um risco maior de envolvimento } \\
\text { extraglandular } \\
\text { subsequente.Recomendam um estudo } \\
\text { com prazo acima de dez anos para } \\
\text { acompanhar pacientes com Síndrome } \\
\text { de Sjögren. }\end{array}$ \\
\hline $\begin{array}{l}\text { Equal rights in autoimmunity: } \\
\text { is Sjo"gren's syndrome ever } \\
\text { 'secondary'? }\end{array}$ & $\begin{array}{l}\text { Kollert; } \\
\text { Fisher; } \\
2020\end{array}$ & $\begin{array}{l}\text { Debater sobre } \text { as } \\
\text { classificações da SS, } \\
\text { discutindo se esses } \\
\text { prefixos obsoletos ou não } \\
\text { nessa terminologia }\end{array}$ & $\begin{array}{l}\text { Existem importantes } \\
\text { consequências não intencionais } \\
\text { da nomenclatura; notavelmente, } \\
\text { a SS 'secundária' foi muito } \\
\text { menos pesquisada r e } \\
\text { frequentemente excluída dos } \\
\text { ensaios clínicos. }\end{array}$ & $\begin{array}{l}\text { Os autores sugerem mais pesquisas } \\
\text { acerca do assunto, tendo critérios para } \\
\text { mudar essas terminologias e utilizar } \\
\text { uma classificação mais rigorosa. }\end{array}$ \\
\hline
\end{tabular}


Após análise das literaturas, foi possível observar que a Síndrome de Sjögren também conhecida como Síndrome da Sicca, apresenta-se de várias formas desde o comprometimento local de glândulas exócrinas até o comprometimento extraglandular sistêmico de vários órgãos. Sua forma multissistêmica de se apresentar requer o acompanhamento de profissionais de várias áreas médicas (Stefanski et al., 2017).

São vários os fatores que estão relacionados com a síndrome, dentre eles: fatores genéticos que aumentam a frequência de alelos HLA-B8/DR3; fatores ambientais como infecções pelo vírus Epstein-Barr influindo na patogênese da SS e fatores hormonais, onde a instabilidade dos hormônios proporcionam o desenvolvimento da Síndrome de Sjogren primária (SSp) (Cavalcante et al., 2017).

A SS é subdividida em Síndrome de Sjögren primária (SSp) e secundária (SSs), onde a primeira é caracterizada por uma infiltração linfocitária nas glândulas exócrinas, resultando na falta de lubrificação das mucosas e consequentemente ressecamento das mesmas; a segunda classificação é caracterizada pelos mesmos sintomas, mais associadas a outras doenças autoimunes como artrite reumatoide, lúpus sistêmico e esclerose sistêmica (Both et al., 2017).

Para Kollert e Fisher, (2020) a classificação da Síndrome de Sjögren não deve ser subdividida em primária e secundária, pois baseado em estudos anteriores as diferenças utilizadas para subdivisão como genes presentes, anticorpos, achados histológicos e aspectos clínicos não apresentam dados relevantes, pois a relação dos achados entre os dois termos, tem diferenças mínimas. A Síndrome de Sjögren que é associada a outra doença autoimune denominada "secundária" acaba sendo pouco conhecida, sub-pesquisada e consequentemente subtratada.

A SS caracteriza-se por sintomas da sicca e manifestações sistêmicas que podem acarretar alterações malignas como o linfoma não Hodgkin, onde há um risco maior em pacientes de idade avançada (Tsukamoto et al., 2018). Essas mutações oncogênicas ocorre pela estimulação crônica das células B, que ao longo tempo irão provocar disfunções no local estimulado (Zerón et al., 2016).

Os diferentes estudos e critérios de classificação reflete em dados de prevalência e incidência heterogêneos, apresentando uma prevalência global para a síndrome de Sjögren primária de 61 por 100.000 habitantes, tendo uma maior prevalência no continente europeu. As pessoas do sexo feminino apresentam uma maior frequência em relação ao sexo masculino numa proporção de 9:1, sendo justificado pela disfunção hormonal. Os primeiros sintomas podem aparecer anos antes do diagnóstico, mais geralmente são diagnosticados tardiamente na média de idade de 56 anos (Stefanski et al., 2017).

O diagnóstico da Síndrome de Sjögren é dificultado por seus sintomas serem relativamente vagos, sendo na maioria das vezes confundidos com outras patologias ou confundidas por reações medicamentosas, levando uma média de 6 a 10 anos desde os primeiros sintomas até o diagnóstico (Bayetto \& Logan, 2010). A falta de critérios de classificação e diagnóstico dificulta a compreensão da prevalência na infância, pois os critérios utilizados para diagnóstico em adultos tornam-se ineficazes, necessitando assim de adaptação e criação de novos critérios. Um dos pontos que devem ser levados em conta é o diagnóstico histopatológico, onde a definição do escore de foco positivo deve ser moldado para o diagnóstico infantil, pois a divergência em relação a pontuação focal em adultos (Lieberman, 2013).

\section{Critérios de Classificação da Síndrome de Sjögren}

Ao longo de décadas vários critérios foram criados para a classificação da SS, visando diferenciar a SSp e SSs além de um diagnóstico precoce e preciso. O grupo American-European Consensus Group em 2002 baseou-se, em pontos como anormalidades em testes oculares (teste de Schirmer), alterações nos testes da mucosa oral avaliando o fluxo salivar, sintomas oculares como o ressecamento ou sensação de corpos estranho no olho, secura da mucosa oral por mais de três meses com aumento da glândula parótida e dificuldade de deglutição, anticorpos circulantes anti-Ro (SSA) e / ou anti-La (SSB) positivos e alteração histológica das glândulas salivares menor como sialadenite linfocítica focal com um ou mais focos de linfócitos 
infiltrantes. Para a classificação da SSp é necessário a presença de quatro desses seis fatores, sendo indispensável a presença de autoanticorpos positivos ou alteração histológica e ausência de outra patologia autoimune associada. Para a SSs é necessário a presença de outra doença autoimune, sintomas de alteração ocular ou oral e mais duas alterações dos tópicos acima mencionadas (Pasoto, 2019).

Em 2012 o American College of Rheumatology (ACR) apresentou novos critérios para a classificação, excluído os critérios de sintomas de sicca e testes das glândulas salivares, modificando o escore de coloração ocular e incluindo novos anticorpos como fator reumatoide (FR) e anticorpos antinucleares (ANA) (Zerón \& Casals, 2014).

Atualmente os critérios de classificação mais aceitos são os descritos pela ACR /Liga Europeia contra o Reumatismo (EULAR) em 2016, onde critérios como sintomas da síndrome sicca e anticorpos anti-La não foram incluídos, tendo peso para diagnósticos a presença de anticorpos anti-Ro positivos, pontuação de van Bijsterveld $\geq 4$, teste de Schirmer $\leq 5 \mathrm{~mm}$ e análise do fluxo salivar não estimulado (Pasoto, 2019). Esses critérios de classificação ACR-EULAR são utilizados especialmente para a SSp, não sendo utilizados para o diagnóstico da SSs (Jonsson et al., 2018).

\section{Funcionalidades das Células B e T}

A ativação das células B é de grande importância na patogênese da síndrome de sjögren e no lúpus eritematoso sistêmico, onde essas células iram ser superestimuladas, juntamente com os plasmócitos de longa vida, formando um arranjo de agregados linfoides nos rins e glândulas salivares desses pacientes. A supraregulação dos interferons reguladores acarretam no aumento de concentração de IFN tipo 1 no tecido e soro de pacientes com SS e LES (Pasoto, 2019).

Os autores Cornec et al., 2012 e Both et al., 2017 afirmam que as células T eram consideradas as iniciadoras do processo autoimune na síndrome de Sjögren primária, mas atualmente as células B vem sendo destaque na fisiopatologia da doença, mostrando-se como ponto principal, pois a ativação dessas células acarretam em hipergamaglobulinemia e produção de diversos autoanticorpos.

As glândulas exócrinas sofrem disfunções conforme as alterações causadas pelos linfócitos periepiteliais infiltrados. A gravidade da doença está relacionada ao número do tipo de células, sendo encontrada em lesões leves o maior número de células T e em lesões graves o maior número de células B (Kyriakidis et al., 2014).

\section{Autoanticorpos}

Para Zerón e Casals (2014) os autoanticorpos são de grande importância para um diagnóstico precoce, pois sua positividade representa a origem autoimune da Síndrome de Sjögren, podendo estar presente vários anos antes do diagnóstico da patologia. Sendo os anticorpos anti-Ro/ La um dos principais marcadores na Síndrome de Sjögren primária, esses anticorpos possuem três funções, sendo marcadores de doença, indicando associação com outras doenças autoimunes e apresentar seu fator patogenético (Huang et al., 2013).

Em pesquisa realizada por Hajiabbasi et al. (2016), 83 pacientes com artrite reumatoide foram analisados para verificar a associação ou não com a Síndrome de Sjögren secundária, onde 90,4\% eram do sexo feminino. A SSs foi diagnosticada em 5 pacientes, sendo todas mulheres que sofriam com artrite reumatoide a mais de 2 anos, tendo uma média de aproximadamente 5 anos entre o diagnóstico da AR e SS. Desse grupo, $80 \%$ apresentaram xeroftalmia e $80 \%$ apresentaram xerostomia. $40 \%$ dos pacientes de AR associados com SS apresentaram anti-RO ou anti-La, já pacientes de AR sem associação com SS representaram apenas 25,6\% de autoanticorpos positivos, não sendo estatisticamente significativo.

Em estudo realizado no Hospital Universitário Keio, foi realizado uma triagem em 224 pacientes que procuraram o hospital, onde 91 pacientes com Síndrome de Sjögren foram acompanhados por 10 anos. Onde 97\% dos pacientes eram do sexo feminino e apenas 3\% do sexo masculino. Para auxílio de diagnóstico da SS esses pacientes apresentaram positividade em 
anticorpo como FAN (84\%), anti-SSA (79\%) e fator reumatoide (36\%). Além disso, 29\% dos pacientes que no diagnóstico inicial da síndrome apresentaram o fator reumatoide negativo, ao logo dos dez anos, positivaram para o anticorpo (Tsukamoto et al., 2018).

Pacientes com HLA-DR3 e HLA-DR2 positivos apresentam maiores níveis de anticorpos anti-Ro/ SSA e anti-La/ SSB, assim o HLA classe II apresenta-se no início de uma resposta imune podendo se estender por vários anos, apesar de sua presença ainda não há uma correlação com as manifestações clínicas (Molina et al., 2011).

Pesquisas mostram que o antígeno alfa-fodrin são proteínas de ligação à actina, que quando clivadas induz a destruição de glândulas exócrinas causadas pelas respostas autoimunes e se fazem presentes em 95,3\% com SSp e 62,5\%, mais em estudo realizado por Nisihara e colaboradores (2016), foram analisados 90 pacientes que tinham artrite reumatoide com e sem a presença de SS, onde foram analisados os antígenos anti-AF $\operatorname{IgG}$ e anti-AF $\operatorname{IgA}$, onde seus resultados não apresentaram diferença significativas entre pacientes com e sem SSs.

\section{Considerações Finais}

A Síndrome de Sjögren é uma doença autoimune, que como as outras ainda não tem origem definida. Apesar de ser a segunda doença autoimune mais frequente, a população não tem conhecimento sobre ela. A necessidade de vários aspectos clínicos e sistêmicos que muitas vezes são sutis, retarda o diagnóstico precoce da doença. Para ajuda diagnóstica é necessário a pesquisa de autoanticorpos, onde a literatura apresenta os autoanticorpos anti-Ro e anti-La como os mais frequentes no diagnóstico.

Com a carência de informações relacionadas a síndrome, principalmente no Brasil, vê-se necessário novos estudos com objetivo de informar a população e desenvolver novos métodos diagnósticos que possam ser mais rápidos e eficazes, proporcionando o bem estar para esses pacientes.

\section{Referências}

Bayetto, K., \& Logan, R. M. (2010). Sjögren's syndrome: a review of aetiology, pathogenesis, diagnosis and management. Australian Dental Journal, 55 Suppl 1, 39-47. https://doi.org/10.1111/j.1834-7819.2010.01197.x

Betim, F., Souza, S., Gomes, R., \& Ribeiro, C. (2015). Da Descoberta às Perpectivas da Síndrome de Sjögren: uma Revisão de Literatura. Revista Eletrônica Biociências, Biotecnologia e Saúde, Curitiba, 13, 20-31.

Both, T., Dalm, V. A. S. H., Martin van Hagen, P., \& Van Daele, P. L. A. (2017). Reviewing primary Sjögren's syndrome: Beyond the dryness - From pathophysiology to diagnosis and treatment. International Journal of Medical Sciences, 14(3), 191-200. https://doi.org/10.7150/ijms.17718

Cavalcante, W., Lorenço, S., Florezi, G., Bologna, S., Hsieh, R., Vanini, J., Antunes, M., Paula, F., Pasoto, S., Silva, L., \& Nico, M. (2017). Síndrome de Sjögren primária : aspectos relevantes para os dentistas. Clinical and Laboratorial Research in Dentistry, 1-11.

Cornec, D., Devauchelle-Pensec, V., Tobón, G. J., Pers, J. O., Jousse-Joulin, S., \& Saraux, A. (2012). B cells in Sjögren’s syndrome: From pathophysiology to diagnosis and treatment. Journal of Autoimmunity, 39(3), 161-167. https://doi.org/10.1016/j.jaut.2012.05.014

COSTA, A. P. DA, JUNIOR, A. C. S., \& PINHEIRO, A. L. (2019). Fatores Associados À Etiologia E Patogenese Das Doenças Autoimunes. Arquivos Catarinenses de Medicina, 48(2), 92-104.

Estrela, C. (2018). Metodologia Científica: Ciência, Ensino, Pesquisa. Editora Artes Médicas.

Flament, T., Bigot, A., Chaigne, B., Henique, H., Diot, E., \& Marchand-Adam, S. (2016). Pulmonary manifestations of Sjögren's syndrome. European Respiratory Review, 25(140), 110-123. https://doi.org/10.1183/16000617.0011-2016

Gomes, R., Brandalise, R., Alba, G., Flato, U., \& Júnior, J. (2010). Síndrome de Sjögren primária. Revista Da Sociedade Brasileira de Clínica Médica, 8(3), $254-265$.

Hajiabbasi, A., Masooleh, I. S., Alizadeh, Y., Banikarimi, A. S., \& Ghavidel Parsa, P. (2016). Secondary sjogren's syndrome in 83 patients with rheumatoid arthritis. Acta Medica Iranica, 54(7), 448-453.

Huang, Y. F., Cheng, Q., Jiang, C. M., An, S., Xiao, L., Gou, Y. C., Yu, W. J., Lei, L., Chen, Q. M., Wang, Y., \& Wang, J. (2013). The immune factors involved in the pathogenesis, diagnosis, and treatment of Sjogren's syndrome. Clinical and Developmental Immunology, 2013. https://doi.org/10.1155/2013/160491 
Research, Society and Development, v. 10, n. 7, e41010716989, 2021

(CC BY 4.0) | ISSN 2525-3409 | DOI: http://dx.doi.org/10.33448/rsd-v10i7.16989

Jonsson, R., Brokstad, K. A., Jonsson, M. V., Delaleu, N., \& Skarstein, K. (2018). Current concepts on Sjögren's syndrome - classification criteria and biomarkers. European Journal of Oral Sciences, 126, 37-48. https://doi.org/10.1111/eos.12536

Kollert, F., \& Fisher, B. A. (2020). Equal rights in autoimmunity: Is Sjögren's syndrome ever "secondary"? Rheumatology (United Kingdom), 59(6), 12181225. https://doi.org/10.1093/rheumatology/keaa009

Kyriakidis, N. C., Kapsogeorgou, E. K., \& Tzioufas, A. G. (2014). A comprehensive review of autoantibodies in primary Sjögren's syndrome: Clinical phenotypes and regulatory mechanisms. Journal of Autoimmunity, 51, 67-74. https://doi.org/10.1016/j.jaut.2013.11.001

Lieberman, S. M. (2013). Childhood Sjögren syndrome: Insights from adults and animal models. Current Opinion in Rheumatology, 25(5), 651-657. https://doi.org/10.1097/BOR.0b013e328363ed23

Molina, G., Alegre, G., \& Peregrina, M. (2011). The meaning of anti-Ro and anti-La antibodies in primary Sjögren's syndrome. Autoimmunity Reviews, 10(3), 123-125. https://doi.org/10.1016/j.autrev.2010.09.001

Nisihara, R., Skare, T. L., Cenci, E., Gabardo, D., Nass, F., \& Utiyama, S. R. R. (2016). Anti-alpha-fodrin antibodies in patients with Sjögren's syndrome secondary to rheumatoid arthritis. Jornal Brasileiro de Patologia e Medicina Laboratorial, 52(3), 137-141. https://doi.org/10.5935/1676-2444.20160023

Pasoto, S. G., Martins, V. A. de O., \& Bonfa, E. (2019). Sjögren's syndrome and systemic lupus erythematosus: Links and risks. Open Access Rheumatology: Research and Reviews, 11, 33-45. https://doi.org/10.2147/OARRR.S167783

Santos, A., Bruno, M., Sandoval, P., Albanesi, R., Flores, R., Zanine, R., \& Zanini, R. (2013). SÍNDROME DE SJÖGREN. Journal of Biodentistry and Biomaterials - Universidade Ibirapuera São Paulo, 3, 47-54.

Santos, L., Barbalho, J., Bartoli, M., Amaral, M., \& Vasconcelos, B. (2013). Síndrome de Sjogren Primária - relato de caso. Cir. Traumatol. Buco-Maxilo-Fac, $13(2), 63-68$

Stefanski, A. L., Tomiak, C., Pleyer, U., Dietrich, T., Burmester, G. R., \& Dörner, T. (2017). The diagnosis and treatment of Sjögren's syndrome. Deutsches Arzteblatt International, 114(20). https://doi.org/10.3238/arztebl.2017.0354

Tsukamoto, M., Suzuki, K., \& Takeuchi, T. (2018). Ten-year observation of patients with primary Sjögren's syndrome: Initial presenting characteristics and the associated outcomes. International Journal of Rheumatic Diseases, 22(5), 929-933. https://doi.org/10.1111/1756-185X.13464

Zerón, P. B., Baldini, C., Bootsma, H., Bowman, S. J., Jonsson, R., Mariette, X., Sivils, K., Theander, E., Tzioufas, A., \& Ramos-Casals, M. (2016). Sjögren syndrome. Nature Reviews Disease Primers, 2(July), 1-20. https://doi.org/10.1038/nrdp.2016.47

Zerón, P. B., \& Casals, M. R. (2014). Advances in the understanding and treatment of systemic complications in Sjögren's syndrome. Current Opinion in Rheumatology, 26(5), 520-527. https://doi.org/10.1097/BOR.0000000000000096 